\title{
Ilse Fusková. El cuerpo como archivo
}

\section{Ilse Fusková. The body as archive}

DOI:10.12957/ek.2019.49545

\section{Dra. Karina Bidaseca* karinabidaseca@yahoo.com.ar} Profesora de Universidad Nacional de San Martín

Este proyecto se inscribe en una línea de investigación transdisciplinaria sobre procesos de archivo de artistas feministas y nuevas tecnologías iniciados en el Programa Poscolonialidad, pensamiento fronterizo y transfronterizo en los estudios feministas con sede en IDAES/UNSAM. Una teoría del archivo entendida como política de lectura es una política de intervención cultural y de democratización del conocimiento, como una práctica de memoria viva. Abordaremos la investigacion sobre la obra de la fotógrafa, reportera y artivista argentina Ilse Fusková -primero feminista y luego asumida como lesbiana-, nacida en el año 1929 en Buenos Aires, desde la teoría feminista y cuir. Su presencia en la escena cultural porteña en los años de 1950, vedada para las mujeres, le permitió tanto a ella como a las lectoras de las revistas en las que ella escribía, abrir la posibilidad de perforar el orden de la dominación patriarcal. Su cuerpo es el archivo vivo de nuestra historia feminista y disidente.

\section{PALABRAS CLAVE Isle Fusková. Cuerpo. Archivo}

This project is part of a line of transdisciplinary research on archiving processes of feminist artists and new technologies at the Postcoloniality Program, border and cross-border thinking in feminist studies based in IDAES / UNSAM. A file theory understood as a reading policy is a policy of cultural intervention and knowledge democratization, as a practice of living memory. We will address the research on the work of the argentinian photographer, reporter and artivist Ilse Fusková first feminist and then assumed as a lesbian - born in 1929 in Buenos Aires, from feminist theory and cuir. Her presence in the Buenos Aires cultural scene in the 1950s, forbidden for women, allowed her as well as the readers of the magazines in which she wrote, to open the possibility of piercing the order of patriarchal domination. His body is the living archive of our feminist and dissident history.

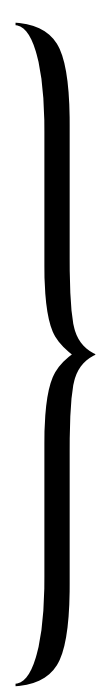

KEYWORDS Ilse Fusková. Body. File 
\begin{tabular}{c|c} 
Ilse Fusková. & Dra. Karina \\
El cuerpo como archivo & Bidaseca [USAM-AR]
\end{tabular}

\title{
Introducción
}

\author{
"Una mujer que ama a otras mujeres \\ sexual y/o no sexualmente. \\ Aprecia y prefiera la cultura de las mujeres, \\ la flexibilidad emocional... \\ y la fuerza de las mujeres." \\ Alice Walker ${ }^{l}$
}

\begin{abstract}
"Existen muchas clases de poder; los que se utilizan y los que no se utilizan, los reconocidos o los que apenas se reconocen. Lo erótico es un recurso que reside en el interior de todas nosotras, asentado en un plano profundamente femenino y espiritual, y firmemente enraizado en el poder de nuestros sentimientos inexpresados y aún por reconocer. Para perpetuarse, toda opresión debe corromper o distorsionar las fuentes de poder inherentes a la cultura de los oprimidos de las que puede surgir energía para el cambio. En el caso de las mujeres, esto se ha traducido en la supresión de lo erótico como fuente de poder e información en nuestras vidas."
\end{abstract}

Audre Lorde.

Algunas de las reflexiones más significativas sobre archivos de artistas fueron generadas en aquellos lugares en los que existe una política de conservación de la memoria escrita. En general, los manuscritos y otro tipo de documentos personales, eran desestimados. Desde un punto de vista epistemológico, pensar el archivo como política de lectura desde un lugar de enunciación como es el Sur Global, permite además observar las marcas de la modernidad colonial en la producción de conocimiento.

El archivo es un lugar de enunciación. Analizar la obra no publicada de una artista es también interpretar la historia de nuestras prácticas artivistas que fundaron las llamadas "feministas históricas" en la Argentina. Es el caso de Ilse Fusková -o Felka, pseudónimo con el que firma sus fotografías de los años 50-,

1 Cita en el Continuum lesbiano."En busca de los jardines de nuestras madres". Walker es autora de El color púrpura. 
quien estudió periodismo mientras se desempeñaba como azafata. Colaboró con reportajes y comentarios de cine en revistas como El Hogar, Chicas, Histnium, Mundo Argentino, Para Ti y Lyra.

La fotografía le permitía salir del espacio doméstico y experimentar la libertad de la ciudad moderna, para unirse, una década más tarde, al Movimiento de Liberación Femenina de fines de los años de 1970. Las publicaciones de sus críticas que comenzarían a aparecer en las revistas mencionadas, hicieron posible ciertos tipos de activismos, aún en condiciones de una dictadura atroz: "En este contexto de militancia feminista, Ilse Fusková lleva a cabo una profunda reflexión sobre la mirada de la mujer y la construcción de la identidad a través del desnudo femenino, con el que busca ampliar los cánones tradicionales de su representación fotográfica.” (Catálogo Walden Gallery, Ilse Fusková. La libertad de pasear sola, 2019). Este es el inicio de la Serie fotográfica El zapallo (1982). Es en el Taller Lugar de Mujer, uno de los primeros espacios creado en 1983, en la naciente democracia, en el que va a exponer esta obra, y en donde realiza sus primeras acciones militantes y prácticas feministas y, luego, lésbicas.

La intervención en los archivos curados por la historiadora del arte, amiga y profunda conocedora de su obra, María Laura Rosa, como conformación de un proceso artístico-cultural, se concibe desde una mirada que no va al archivo como quien va a observar la reiteración de un pasado estático, sino que en él encuentra la huella de un acontecimiento que contiene otras luchas. Esos momentos politicos van a ir constituyendo una conciencia histórica dentro del movimiento feminista y cuir.

La despatoligización de la homosexualidad fue un momento clave en su trayectoria. En 1971 integrantes del Grupo Nuestro Mundo junto a militantes de izquierda fundaron el Frente de Liberación Homosexual (FLH) entre cuyos integrantes se hallaba Nestor Perlongher, Juan José Sebrelli y Manuel Puig. Se relacionaban con las organizaciones feministas. En 1975, luego de que un artículo firmado por José Lopez Rega titulado: "Hay que acabar con los homosexuales", esta organización tuvo que pasar a la clandestinidad.2

\footnotetext{
2 En una entrevista reciente, Césa Cigluitti, actual Presidente de la Comunidad Homosexual Argentinas CHA y uno de los organizadores de la $1^{\circ}$ Marcha del orgullo recuerda: "No había manera de ir por la calle y que te dejaran en paz. Íbamos con Carlos al supermercado y había gente que lo insultaba en la cara. En esa época todavía estaban vigentes los edictos policiales: te llevaban por 'incitación al acto carnal en la vía pública' o por 'exhibirse con ropa del sexo contrario'. No es que los gays camináramos de la mano o nos besáramos en público: te llevaban por portación de cara. Carlos y yo nos conocimos todas las comisarías de la Ciudad de Buenos Aires sacando gays y travestis". https://www.infobae.com/sociedad/2019/11/02/fue-una-pieza-clave-en-la-1-marcha-del-orgullo-y-cuenta-sus-secretos-anos-de-lucha-detras-de-una-noche-marcada-por-un-golpe-de-suerte/
} 
Casi dos décadas más tarde, Ilse une a Gays por los Derechos Civiles y junto a Carlos Jáuregu 1992 la primer marcha del orgullo "gay" -luego LGBTTQ+en Buenos Aires (ROSA, 2019). En este tiempo, esas prácticas novedosas "estarían indicando, lanzando, experimentando modos alternativos, disidentes, "contraculturales" de subjetivación. Su interés, residiría, entonces, en que abren "puntos de fuga" para la implosión de cierto paradigma normativo de personalidad social. (PERLONGHER, 2016: 67-68).

Por un lado, el significante 'queer' cristaliza una forma de activismo basado en una política anti-asimilacionista, de coaliciones y alianzas, así como en una estrategia de confrontación pública y directa, las cuales han dejado sus marcas en las formas de activismo contemporáneo.

$(\text { SABSAY, 2014) })^{3}$

El surgimiento de lo nuevo que acontece en el mundo, implica también la resignificación de emergencias que irrumpen en este caso como marca distintiva de los procesos de escritura y de archivación. Estas marcas, como vehículos de memoria, nos permiten interpretar la obra de Fusková como legado intergeneracional. Cabe destacar entre tantos, su rol de traductora en varias lenguas de textos y debates de las vertientes feministas de los Estados Unidos, Inglaterra, Francia, o Italia, que la artista traducía para la audiencia feminista argentina. Un modo de aproximar las luchas del movimiento entre ambas orillas, a partir de manuscritos que se leían y discutían en círculos de lectura en los primeros espacios de la militancia, fueron escribiendo la historia del las subalternas. El activismo artístico o artivisimo, comúnmente tiene lugar en emplazamientos públicos. Es clave el trabajo en red colectiva (con otros grupos, asociaciones, movimientos sociales) y se caracteriza por el predominio de las acciones performáticas, a veces conectadas con los medios de comunicación.

En lo que sigue, abordaremos la obra de Fusková desde dos lugares: 1. cuerpo-archivo-memoria (ANTONACCI, 2018) 4; 2. Manuscritos de la artista inéditos y publicaciones de la época, desde la transdisciplina, esa zona fronteriza

3 El uso de la palabra queer se reconoce en 1991 con el artículo "Queer Theory. Lesbian and gay sexualities" publicado en la revista Diferenssies.

4 "Em metáfora visual, conjugando cosmo/corpo/cultura, sua memória expandiu-se em redes de comunicações orais", Antonacci (2018). Tomando del libro de Diana Taylor, dice la etnohistoriadora: "A performance, para mim, funciona como uma episteme, um modo de conhecer, e não simplesmente como objeto de análise." O Arquivo e o Repertório: performance e memória cultural nas Américas, Belo Horizonte: Editora da UFMG, 2013. 
en la que la crítica del arte dialoga con otros saberes que se interrumpen unos a otros, como dice la crítica Nelly Richard, con respuestas siempre parciales para evitar cualquier totalización del conocimiento (2014: 18). Proponemos repensar los abordajes metodológicos que, tradicionalmente se han utilizado, desde un enfoque socio-afectivo fraguado en la amistad entre mujeres, en la hermandad propiciada por el afrofeminismo (Audre Lorde5) fundada en una "poética erótica de la Relación" (BIDASECA, 2017) y en una etnografía feminista post-heroica (BIDASECA, 2018).6

\section{Las vidas de Ilse Fusková}

Nació en Buenos Aires, en 1929. Es una de las más destacadas referentes del lesbofeminismo en la Argentina. "La lesbiana ilustre", tal como la llaman, luego de ser homenajeda por la Ciudad de Buenos Aires en 2015.

Sus vidas son múltiples, como son sus nombres. De padre alemán y madre checoslovaca. Fue Feska en los 50. A fines de los años 70, antes de divorciarse llevaba el apellido de su esposo -común en esa época-. Fue Ilse Kornreich. Luego, durante algunos años llevó el apellido paterno y se llamó Ilse Wünhe. Finalmente, al aumirse lesbiana en el III Encuentro Feminista Latinoamericano y de Caribe que se realizó en Bertioga (Brasil) en 1985, adoptó el apellido de su madre. Es Fusková, como se la conoce hoy.

\footnotetext{
5 Existen muchas clases de poder; los que se utilizan y los que no se utilizan, los reconocidos o los que apenas se reconocen. Lo erótico es un recurso que reside en el interior de todas nosotras, asentado en un plano profundamente femenino y espiritual, y firmemente enraizado en el poder de nuestros sentimientos inexpresados y aún por reconocer." (Lorde, 1978)

6 Este abordaje refiere a la crítica a la universalización del lenguaje etnográfico y del principio maestro que funda lo que defno como el "heroicismo androcéntrico". A partir de la lectura de etnografías realizadas por mujeres feministas del sur, se indaga en una serie de solapamientos y descentramientos de las voces femeninas consideradas como lenguas minoritarias y, asimismo, en el tratamiento de las "nativas" subalternas y las etnógrafas en zonas de fronteras y escenas bélicas. Las "etnografías multisituadas" surgidas en el Norte global, como modalidad relativamente novedosa para el desafío de las hegemonías globales, demostraron que el centro del análisis etnográfico contemporáneo no se encuentra en reclamar algún estado cultural previo, sino en las nuevas formas culturales que han surgido en las situaciones coloniales subalternizadas. Esta etnografía móvil toma trayectorias inesperadas al seguir formaciones culturales a través y dentro de múltiples sitios de actividad. No obstante, desafiar las hegemonías globales sigue siendo un reto para la desestabilización de las formas convencionales que han solapado otros saberes no hegemónicos anticoloniales y antipatriarcales producidos en el Sur. Ver, Bidaseca (2018b).
} 


\section{Felka. La Ilse de los años 50}

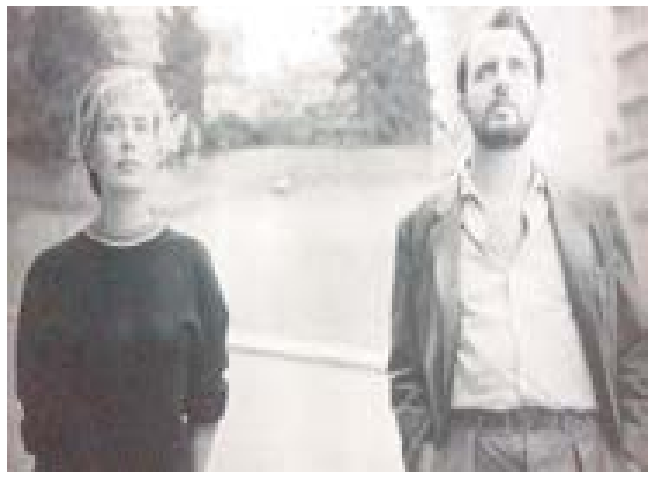

Felka y Greco en el Pasaje porteño Seaver.

Felka fue el seudónimo que utilizó para firmar sus fotografías de los años cincuenta. "Felka, era el nombre de una azafata húngara que trabajó conmigo y que me gustaba mucho", comentaría en la entrevista realizada por Mabel Bellucci (2006). En una nota "La fotografía, como la vemos tú y yo" de 1954, aparecida en la Revista Chicas, Felka comenta: "No digamos que la fotografía es una profesión de mujeres. Pero sí que es una profesión en la que la mujer se siente cómoda" (p. 22-23, apud ROSA, 2019 , p. 10). En efecto en una entrevista señala: "La foto no era un arte de dominio totalmente masculino. Como fue una disciplina tan cuestionada, sufría menos el machismo de las "Bellas Artes" (apud PÁGINA12/SOY, 2018).

Feska llega a comprar una cámara Nikon, cuando alcanza su emancipación económica. A mediados de los 40 comenzaba a expandirse la aviación comercial, las naves eran aviones de hélice e Ilse, por su manejo de varias lenguas, consiguió su primer trabajo siendo adolescente en Scandinavian Airlines.

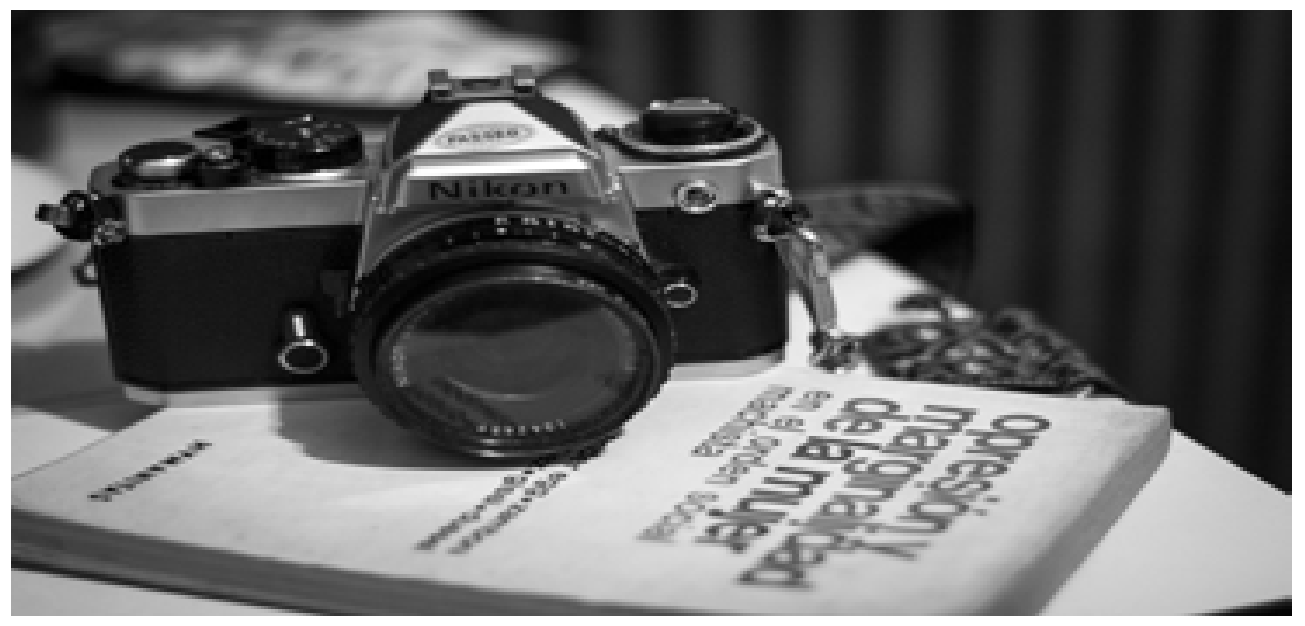

Fuente: http://www.hamartia.com.ar/2019/03/28/la-camara-de-felka

Su trabajo como azafata, en tiempos en que los vuelos transocéanicos eran a hélice y, llegar a Europa implicaba escalas de una semana en Rio de Janeiro y en Dakar, le permitió poder elegir otro trabajo. 
En 1948 había aparecido Chicas, una revista de tirada mensual dirigida por Guillermo Devito. Su impulso la llevó a pedir una entrevista para proponer un espacio que cuestionara el lugar que el periodismo les reservaba a las mujeres: moda, cocina, reuniones sociales y horóscopos. Expresé mis ganas de escribir una columna con todo lo que venía experimentado como azafata al conocer otros modos de vida que reflejaban el estilo de una mujer moderna: autónoma, liberada de las obligaciones hogareñas y maternales. (apud BELLUCCI, 2006)

Allí comenzó a hacer críticas de películas, de muestras de arte y reportajes. “Al principio, mi columna no tenía título, la ilustraba mi foto con el uniforme de las aerolíneas y firmaba bajo el seudónimo Felka (...). La revista no solo era leída por mujeres sino también por gays", cuenta en esa entrevista (IDEM).

Según María Laura Rosa, la Ilse de los 50 tiene una mirada de rescate de las mujeres de los circuitos culturales en el marco de una sociedad que recién estrenaba el voto femenino en 1949.

Muy pocas mujeres lograrían transitar solas por las calles sin sospechas. "Contemplábamos en silencio aquella ciudad que se mostraba moderna y exultante", dice en una entrevista (apud JÁUREGUI, 2018). Ella andaba con un varón gay, Alberto Greco. "Necesitaba de esa compañía para circular en el espacio público con más libertad." (apud PÁGINA12/SOY, 2018). La bohemia artística e intelectual se movía por la calle Viamonte, entre Florida hasta Plaza San Martín. Cuenta que el auge de esa zona comenzó a mediados de los ' 40 por una confluencia de instituciones: la Facultad de Filosofía y Letras, la redacción de la revista Sur, el Instituto de Arte Moderno y el teatro Los Independientes, así como numerosas galerías de arte.

Solíamos encontrarnos en el bar Florida Garden. Algunos lo llamaban el bar existencialista por los habitués de vanguardia que usaban barba, fumaban pipa, leían horas enteras, intercaladas con discusiones interminables. Yo tenía fascinación por la pintura moderna. Una tarde de invierno fui a una exposición en una galería en Viamonte y Florida. De pronto, alguien se acercó para preguntarme si yo era Felka: "Sí, soy yo", respondí. Entonces él se presentó: "Soy Alberto Greco", me dijo. A partir de ese instante, nunca más nos separamos. Compartíamos las mismas cosas. Tanto Greco como yo hacíamos lo que teníamos ganas de hacer. Amaba con pasión. Nunca me dijo que era homosexual. Me contaba sobre sus relaciones sin hacer referencia al sexo. 


\section{$(\ldots)$}

Hasta en su suicidio fue de una radicalidad poética. Escribió sobre su mano izquierda la palabra "Fin" y sobre la pared: "Esta es mi mejor obra". (apud BELLUCCI, 2006).

En julio de 1957 Fusková deja de realizar reportajes y en julio de ese año expone Santa María del Buen Aire en la Galería del Quetzal de la Facultad de Derecho y Ciencias Sociales de la Universidad de Buenos Aires, una serie de fotografías que incluyeron textos de Greco. Quizá fuera el último de los encuentros entre ambos antes de su partida.

\section{Ilse Kornreich vs Ilse Wünche}

"En 1979, gracias a un anuncio que aparece en el periódico Buenos Aires Herald de la Revista Persona, Fusková toma contacto con María Elena Oddone, fundadora del Movimiento de Liberación Femenina" 7(JÁUREGUI, 2018). Cuenta: "Yo me contacto con ella en dictadura y me vuelco al feminismo. Ella traía libros (del extranjero) y los vendía: Carla Lonzi, Juliet Mitchell." (ROSA, 2019 , p. 28). En esos años, algunas lecturas del feminismo de la segunda ola como El Segundo Sexo, de Simone de Beauvoir, o Heterosexualidad obligatoria y existencia lesbiana de Adrienne Rich8 se vuelven obras fundamentales y clásicos del feminismo de los años '60, pero de difícil llegada en el sur. El último es un texto imprescindible para el movimiento (político) de lesbianas, pero es apenas uno de los aportes fundamentales de la poeta y ensayista norteamericana. Dentro de los Veinte poemas de amor y una canción desesperada, escritos por Pablo Neruda, figura aquel inolvidable verso que resalta la "virtud" femenina del silencio: "Me gustas cuando callas porque estás como ausente". En 1976, tres años después de que recibiera el Nobel, Adrienne Rich le presentó batalla publicando sus "Veintiún poemas de amor", contestando aquella poética con su erótica, cuestionaría así la tradición androcéntrica literaria:

7 La revista Persona era una publicación feminista dirigida por María Elena Oddone. Ilse Fusková conoció a la fundadora del Movimiento de Liberación Femenina, a través de Grete Stern y su marido Horacio Cóppola.

8 Originalmente se publicó como Adrienne Rich, Compulsory Heterosexuality and Lesbian Existence, en Ead., Blood, Bread, and Poetry. Selected Prose 1979-1985. Nueva York y Londres: Norton, 1986,23-75. 


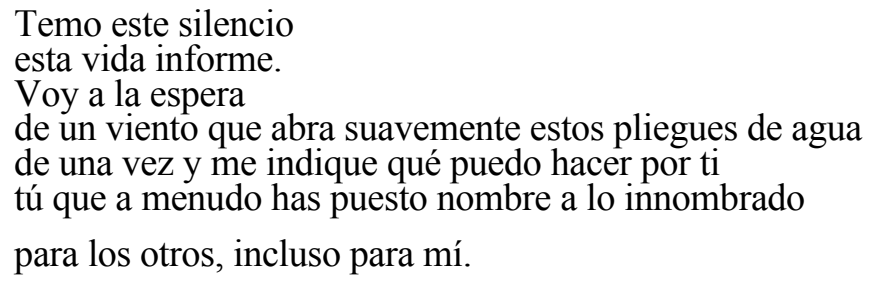

Para Rich, la revolución pasó, sigue pasando, por desenmascarar el poder que el lenguaje tiene sobre las cosas. "...éste es el lenguaje del opresor/ y sin embargo lo necesito para hablarte", dijo en 1968. En 1980 propuso los términos de "existencia lesbiana" ("porque con decir lesbiana no alcanza para afirmar una presencia histórica omitida") y "continuum lésbico" (una cadena de solidaridades y empoderamiento mutuo entre las mujeres, para el cual no es condición la vinculación erótica). El 8 de marzo de 1987 apareció el primer número de Cuadernos de Existencia Lesbiana que co-editó junto a Adriana Carrasco. Fue diseñada como un boletín artesanal y distribuida por ellas mismas. Comenzaron a venderlos con muchas dudas, cuenta, en la marcha del Día Internacional de la Mujer.

En un texto titulado el "Continuum lesbiano" publicado en los Cuadernos y firmado como Ilse Kornreich, la artivista menciona el ensayo de Rich de este modo:

En el conocido ensayo de la poeta norteamericana Adrienne Rich leí por primera vez 1 palabra continuum ${ }^{9}$. Ella explica así de qué se trata: "Si consideramos la posibilidad de que todas las mujeres, desde la lactante hasta la mujer adulta que experimenta sensaciones orgásmicas mientras amamanta a su hija/hijo, recordando el olor lácteo materno a través del suyo propio- pasando por mujeres como Chloe y Olivia de Virginia Woolf que comparten un laboratorio, -hasta la mujer moribunda de 90 años cuidada y ayudada por mujeres- vemos que integran un continuum, tanto si nos identificamos como lesbianas o no. (p. 12)

Suele repetir en diferentes lugares: “¡El feminismo me salvó la vida! Me hizo ver que las cosas que estaba viviendo -la descalificación, la falta de apoyo en la vida doméstica, familiar - eran parte de un sistema. Cuando descubrí esto salí de una profunda depresión" (apud JÁUREGUI, 2018). En efecto, prosigue en su texto de 1989 en el cual reflexiona a partir de Rich, el desprecio o excita-

9 Subrayado con negritas en el original. 
ción de los varones, o la perversidad, anormalidad o inmadurez que el discurso médico patriarcal imponía como legítimo:

Nosotras mismas no hace mucho nos sentíamos en el pozo de la soledad. Pero a partir de los años 70 comienza una refleción autónoma de las mujeres sobre sí mismas. Y somos capaces ahora de sacudirnos lo sucio, negativo y enfermo.Comenzamos a estar orgullosas de amar a otras mujeres. Descubrimos, valoramos, el ingrediente revolucionario del feminismo lesbiano, su lúcido análisas y cuestionamiento de la norma heterosexual, verdaderas dictadura sexual, cuya mayor victoria fue permanecer invisible para las propias mujeres. $(1998$, p. 12)

La Unión Feminista Argentina (UFA) ya había sido fundada en 1970 por María Luisa Bemberg, la italiana Gabriela Cristeller10 y otras feministas que se reunían en los salones del Café Tortoni. Leían algunos textos muy fuertes para la época como el clásico de Carla Lonzi: Escupamos sobre Hegel, Rivolte Femminile. También se leía a Betty Friedan, feminista estadounidense. Contemporáneas a las francesas, quienes en 1970 declaraban en un documento reproducido por la autora en los Cuadernos, lo siguiente:

La heterosexualidad es parte integrante de una sociedad basada en el principio del rendimiento. La homosexualidad no tiene más razón que el deseo. Los homosexuales lucharán por una sociedad futura sin clases y sin penurias, basada en el principio del placer. El lesbianismo es potencialmente revolucionario. Y será revolucionario a condición de que sea: 1) obra de un grupo y no de unas pocas; 2) de que este grupo sea conciente que es político por sus relaciones sociales antipatriarcales; 3) que esta colectvidad política se sitúe dentro de una estrategia que luche contra el conjunto de la familia burguesa y patriarcal (apud KORNREICH, 1989, p. 14)

10 Leonor Calvera, Alicia D’Amico, Sara Torres, Marta Miguelez, Hilda Rais, entre otras se mencionan en Rosa (2019: 28). En 1973 UFA se quiebra, por diferentes motivos. 
La conciencia política fue parte de este movimiento feminista interncional con reivindicaciones claras acerca del funcionamiento del sistema patriarcal, de la opresión y de cómo era posible visibilizar esos mecanismos sutiles para emprender los términos de la liberación. Ilse se transformará en una pionera de esas luchas.

La actividad pública que hacíamos, cuentan era, por ejemplo, volantear para el Día de la Madre por calles y plazas. Había algunos con unos dibujos muy graciosos que aludían a las múltiples tareas de la mujer en la casa, con los niños, los electrodomésticos. El lema era: Madre, reina o esclava, nunca una persona. En el ' 74 , cuando estaba López Rega, salió el decreto de prohibición de anticonceptivos. Nos lanzamos no sólo a volantear, también a estar en la calle Florida hablando con la gente sobre el tema. En el '75, en el Año de Igualdad, Desarrollo y Paz, se armó una coordinadora para organizar los eventos, con mujeres de los partidos políticos, feministas. Ya existía el MLF (Movimiento de Liberación Feminista), creado por María Elena Oddone. Algunas del MLF se vinieron a UFA, empezamos a trabajar con los chicos del FLH (Frente de Liberación Homosexual) que había arrancado porco antes. Nos conectamos porque ellos estudiaban el feminismo y formamos el grupo Política Sexual, inspirándonos en Kate Millett. Ahí estaba Néstor Perlongher, de formación marxista, de una lucidez enorme. Entonces nos juntamos los chicos del FLH, que eran muy jóvenes, y algunas feministas de UFA. Nuestro programa incluía el aborto legal y gratuito, el divorcio, la patria potestad indistinta. Un grupo de ultraizquierda. En ese momento, una probable condena a muerte. Ya habían empezado las desapariciones, sabíamos de gente que pasaba a la clandestinidad. En consecuencia, disolvimos UFA de común acuerdo. ${ }^{11}$

11 En 1981 nace la Organización Feminista Argentina (OFA) -grupo de feministas radicales-, también, LIBERAque se disuelve en 1985 y DIMA. Todas ellas agrupaciones que se forman en torno a objetivos legales. Asimismo, en 1982 se funda ATEM " 25 de Noviembre" Asociación de Trabajo y Estudio de la Mujer, en el mismo año se crea la Librería de la Mujer y, al año siguiente, surge "Lugar de Mujer". 
Un volante de los años 70 de la UFA, dice: "El embarazo no deseado es un modo de esclavitud. Basta de abortos clandestinos. Por la legalidad del aborto. Feminismo en marcha". Bellucci señala cómo la Asociación de Estudios y Trabajo para la Mujer ATEM fue pionero en vincular la violencia política con la violencia sexual. Según esta autora, una gacetilla de prensa firmada por Ilse Kornreich, Graciela Wolfenson y María Ela Oddone, inspirada en los Tribunal de Violencia contra la Mujer (1983) ya hablaría de feminicidio12:

Los feminicidios y vejaciones de todo tipo, que las mujeres sufrimos ordinariamente, quedan como 'hechos privados' y libres de toda sanción. Nosotras declaramos: la violencia sexual es sólo el aspecto más espectacular de una violencia que se repite continuamente, bajo todas las formas. La violencia contra la mujer es una cuestión política. Es un proceso conciente de terrorismo sexual que acompaña al ejercico de poder patriarcal (CECyM, 1996: 34, citado por Bellucci, 2019: 268).

\section{"Apasionadamente lesbiana"}

A nivel artístico, Fusková era prácticamente desconocida dentro del campo local. Como fotógrafa realizó una valiosa investigación sobre la mirada de las mujeres hacia sus propios cuerpos y sobre la representación del deseo lésbico. Las urgencias de los años 80 y 90 fueron las luchas por la patria potestad, por el divorcio, por la "violencia doméstica" y la visibilidad lésbica, momento en el cual la llamada "peste rosa" -HIV fue asociado exclusivamente a la comunidad homosexual y así se justficaba su discriminación. "Pienso que, para esa época, aún era imposible de publicar imágenes positivas de lesbianas. O salíamos en la prensa amarilla o no salíamos en ningún lado. Una foto de mujeres felices, orgullosas de ser lesbianas, no era tolerable para el sistema" (JÁUREGUI, 2018).

En 1984 y 1985, Felka integró el grupo Imagema, que conformaban Cóppola y Juan José Guttero. En 1985 empezó a militar en el feminismo y luego en el

12 El concepto femicide ya estaba circulando a partir de 1974 con el trabajo de Carol Orlock. Para ampliar la genealogías del concepto, puede ver mi trabajo "Feminicidio y políticas de la memoria. Exhalaciones sobre la abyección de la violencia contra las mujeres", publicado por CLACSO, 2014. 
movimiento lésbico-feminista. En 1986 publica un poemario junto con Nelda Guixé Luna en la vereda.

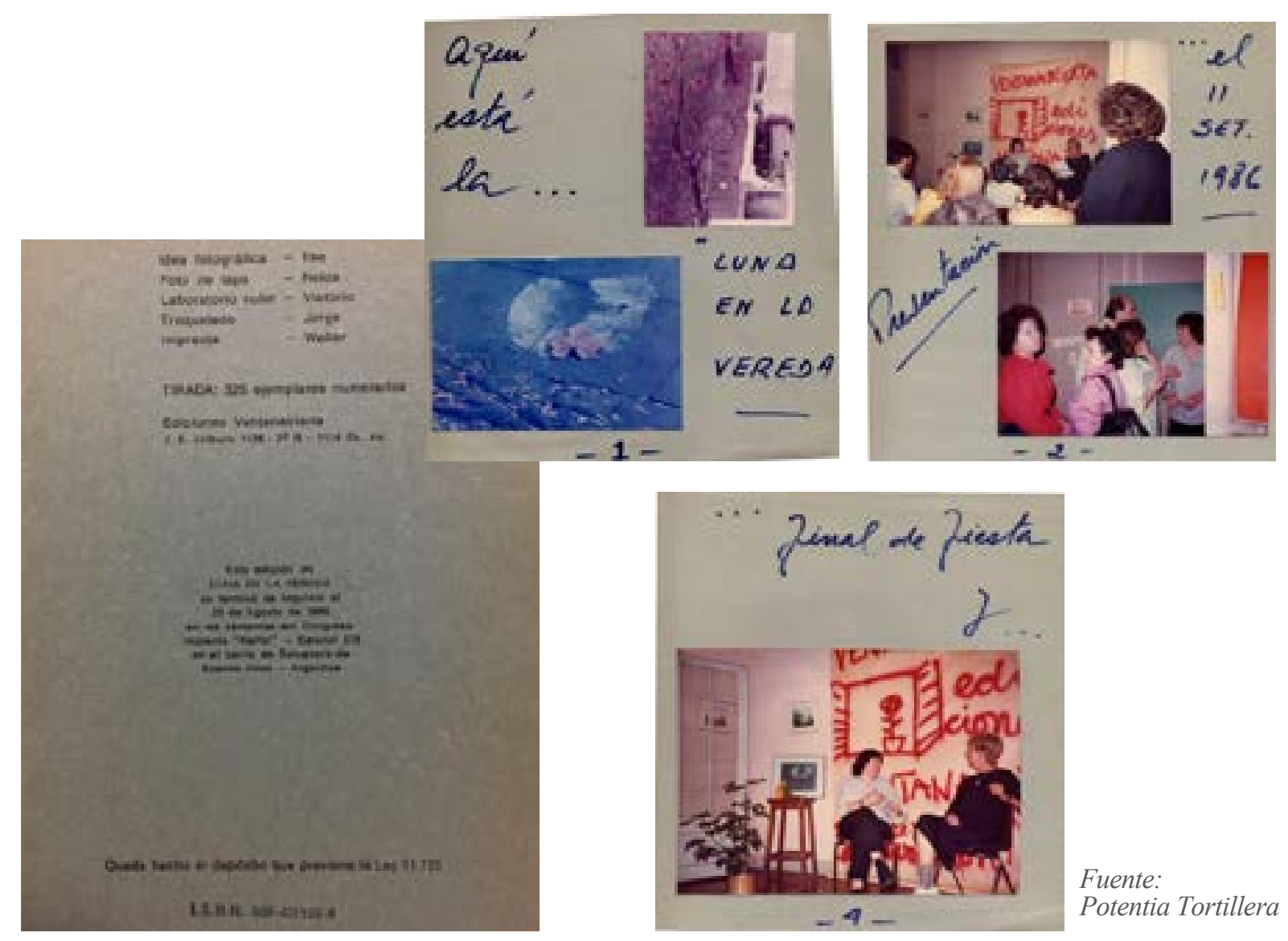

El 8 de marzo de 1987 apareció el primer número de Cuadernos de Existencia Lesbiana que co-editó junto a Adriana Carrasco. Fue diseñada como un boletín artesanal y distribuida por ellas mismas. Comenzaron a venderlos con muchas dudas, cuenta, en la marcha del Día Internacional de la Mujer. Los grupos Reflexión Lesbiana -del espacio Lugar de Mujer- y Cuadernos de Existencia Lesbiana decidieron ingresar a la plaza de los Dos Congresos para participar de la manifestación convocada por la Multisectorial de la Mujer. Llevaban carteles de Cuadernos de Existencia Lesbiana, un estandarte de tela rosa y cada una con una flor en la camisa y una cinta en el pelo que decía: "Apasionadamente lesbiana". Ilse recuerda: 
Ilse Fusková
Dra. Karina

Bidaseca [USAM-AR]

de las feministas, que nos miraban con desdén y trataban de separarse para evitar algún tipo de compromiso. Si no se nos nombraba en un sitio cerrado menos aún en un sitio abierto como era la plaza. Nosotras nos sentíamos unas revolucionarias. Poníamos el cuerpo, la cara y con tan poco apoyo por parte de las feministas, con excepción de Marta Fontenla y Magui Belotti. Todo era un gran interrogante sobre si era o no era peligroso. (JÁUREGUI, 2018).

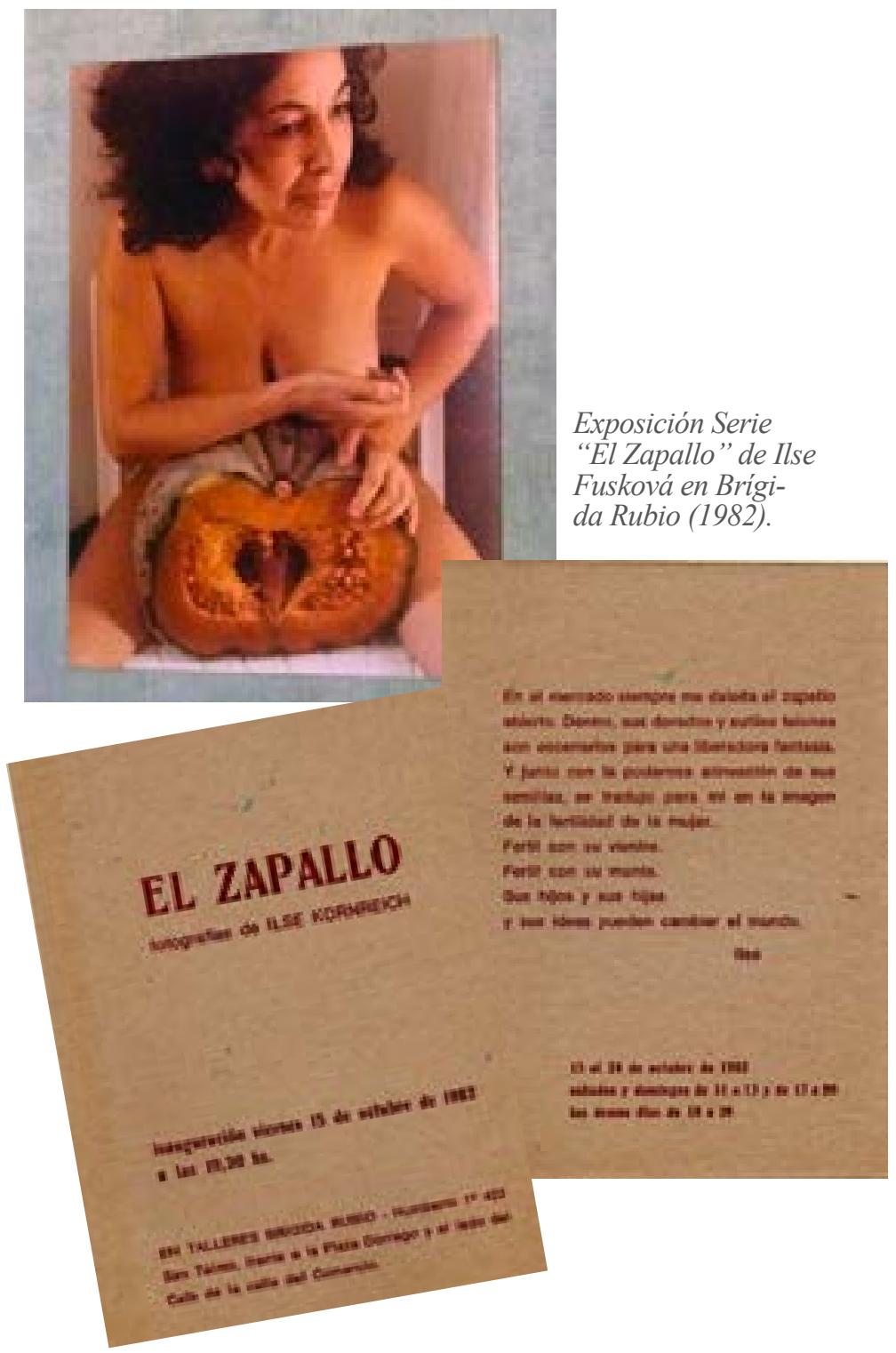




\section{Ilse Fusková. Lo que puede un cuerpo}

Tras dos décadas alejada de la fotografía, y de búsqueda interior, surge la serie fotográfica El zapallo (1982) en los talleres Brígida Rubio, en la calle Humberto $1^{\circ} 422$, San Telmo. El Zapallo consistió en una serie fotográfica integrada por diez trabajos que referían directamente a la fecundidad femenina.

La preocupación de la fotógrafa era cómo representar el cuerpo desnudo de una mujer visto por otra mujer. Romper el foco de la mirada masculina. El cuerpo desnudo de la mujer era un tema tabú por entonces en nuestra sociedad, expresaría Ilse Fusková:

La mayoría de las mujeres en la cultura occidental nos vemos a través de la mirada distorsionada de una sociedad dominada por varones. Esto es verdad para todo nuestro ser y muy especialmente para la percepción que tenemos de nuestro propio cuerpo (...) Yo pienso que

el cuerpo de la mujer es objeto de deseo del macho, que ese cuerpo le fascina y también le da miedo. Sin embargo, el cuerpo desnudo de la mujer, sin las contorsiones de la seducción, es una imagen prohibida (...) La desnudez del cuerpo de la mujer es un derecho que nos es absolutamente negado. (apud ROSA, 2019: 29- 30).

El escenario de esa liberación es el mercado. La mirada de Ilse Fusková se detuvo allí, un espacio que ocupa un tiempo importante en la vida de las mujeres.

Observó las sutilezas, pliegues, semillas y encantos que tenía un zapallo abierto. Así fue que comenzó una investigación sobre el desnudo femenino. (...) Ver zapallos grandes cortados por la mitad era ver un mundo de magia, porque estaban llenos de telones dorados, de semillas. Yo no sé si alguna vez vieron un zapallo así. Para mí era una cosa divina, llena de fertilidad y me dije: 'yo quiero hacer una serie de fotografías con esto'. Me compré, entonces, el zapallo. (JÁUREGUI, 2018)

Se observa así en el poema de la Serie, la liberación de la fantasía se funda en esa fecundidad propia, en la "carnosidad abierta de la verdura" (Rosa, 2019: 29) que se vuelve la sinergia de esa transformación ocurrida en la politicidad 
del cotidiano. Escribe María Laura Rosa: "La serie se detenía poéticamente en dos desnudeces: la del zapallo - en toda su carnosidad interna - y la de la modelo". (2019, p. 29-30). La modelo conocida como Silvia Schmid, trabajaba para el pintor Raul Soldi. La fotografía transmite la erotización de un cuerpo que emana el poder de lograr subvertir el canon. Deja de responder al de la belleza y perfección juveniles; remite a los pliegues y formas del tiempo que dejan su huella en el cuerpo de una mujer madura. La fotografía advierte la fusión del zapallo abierto sostenido en la vagina; manos y brazos se extendien hacia arriba; la redondez de las tetas se confunde con los límites de la verdura, no hay fronteras precisas entre ellas. Las poses experimentadas plasman una poética erótica de la feminidad singular, revelando en la fotógrafa a la artista en su acto de re(ex)istencia. El cuerpo femenino se puede leer como gesto político.

En el movimiento de mujeres de los años 70, la mitología, el matriarcado y culto a las diosas, la espiritualidad influyen definitivamente en su obra. La revista estadounidense Woman of Power, Marija Gimbutas y Merlin Stone y su análisis del culto a las diosas en las culturas neolíticas de Occidente, no fueron adjudicadas a la historia de las diosas.

En 1986 una de las fotografías de la seria es seleccionada para integrar la exposición Mujeres fotografian mujeres, organizada por la Volkshochschule, Munich.

\section{Fusková}

Muchas de nosotras sentimos la natural atracción entre mujeres por primera vez en el $3^{\text {a }}$ Encuentro Feminista en Bertioga, Brasil en 1985. Novecientas mujeres junto al mar en un clima tropical. De noche la pista de baile se cargaba intensamente de energía erótica. La experiencia de que 'sólo mujeres'no significa 'pan con pan, comida de zonzo'. Fue una bella, profunda toma de conciencia de los vínculos que generan una energía transformadora. Y esto vuelve a repetirse en todos los encuentros de mujeres, nacionales e internacionales. (KORNREICH, 1989, p. 12).

La salida del clóset le costó la prohibición paterna de llevar su apellido. Ilse asumió el de su madre. Fusková. Sentía que era una tarea importante para el 


\begin{tabular}{c|c} 
Ilse Fusková. & Dra. Karina \\
El cuerpo como archivo & Bidaseca [USAM-AR]
\end{tabular}

despertar de esa conciencia histórica "rescatar del pasado la relación de amistad entre mujeres (que siempre ha existido pero fue sistemáticamente borrada de la historia oficial)" (p. 12).

Una parte significativa de la investigación de Rosa es la que relata las reflexiones sobre la menstruación que realizaron Ilse Fusková junto a un grupo de compañeras de los Cuadernos de existencia lesbiana. Sus desnudos femeninos reealizados con sangre fueron censurados.

Es el tiempo en que la fotógrafa despierta también a nivel artístico. Rosa reconstruye tres exhibiciones históricas del arte feminista: Mitominas 1, El ama de casa y la locura; y Mitominas 2, llevadas a cabo en 1986, 1987 y 1989 respectivamente. Las Mitominas fueron exhibiciones colectivas de artistas de diferentes artes, que ocuparon la totalidad del Centro Cultural Ciudad de Buenos Aires, hoy Centro Cultural Recoleta. Su objetivo fue el de cuestionar los mitos occidentales.

Las fotografías de las mujeres pintando sus cuerpos con sangre menstrual, pensadas para ser exhibidas en la exposición Mitominas 2: los mitos de la sangre, fueron el origen de un conflicto dentro del grupo de las mitominas mismas, las cuales votaron para su censura. Esta parte de la investigación de Rosa refleja las dificultades de las lesbianas para hacer oír sus voces, dentro de los mismos movimientos de mujeres, los que por largo tiempo invisivilizaron a las feministas lesbianas. (GLUZMAN, 2017).

En 1988 presentó una serie fotográfica para la segunda edición de Mitominas II. Los mitos de la sangre, en el Centro Cultural Ciudad de Buenos Aires del 4 al 27 de noviembre.

La serie fotográfica inspirada en el informe Hite de la socióloga y sexóloga estadounidense, de origen alemán, Shere Hite, mostraba en cinco fotografías una pareja de lesbianas pintando su cuerpo con sangre menstrual. La serie fotográfica sobre la sangre de 1988, nunca fue exhibida desde su realización. Con este trabajo, Ilse Fusková expuso las contradicciones dentro del colectivo lésbico que, ante el temor a la exclusión, prefirieron censurar antes que ser censuradas. (ROSA, 2014) 
El día de la inauguración de "Mitominas 2. Los mitos de la sangre" y en repudio la censura de las feministas realiza junto a Susana Muñoz la performance de los tampones. Cuenta Ilse en la presentación de su libro:

Nosotras preparamos una gran bandeja de plata que tenía en mi casa con unos canapés. Colocamos sobre hojas verde de lechugas los tampones. Los repartimos en el momento de la apertura de la muestra y estaban tan bien hecho que algunos varones se los llevaron a sus bocas! Con Susana nos escapamos muertas de risa.

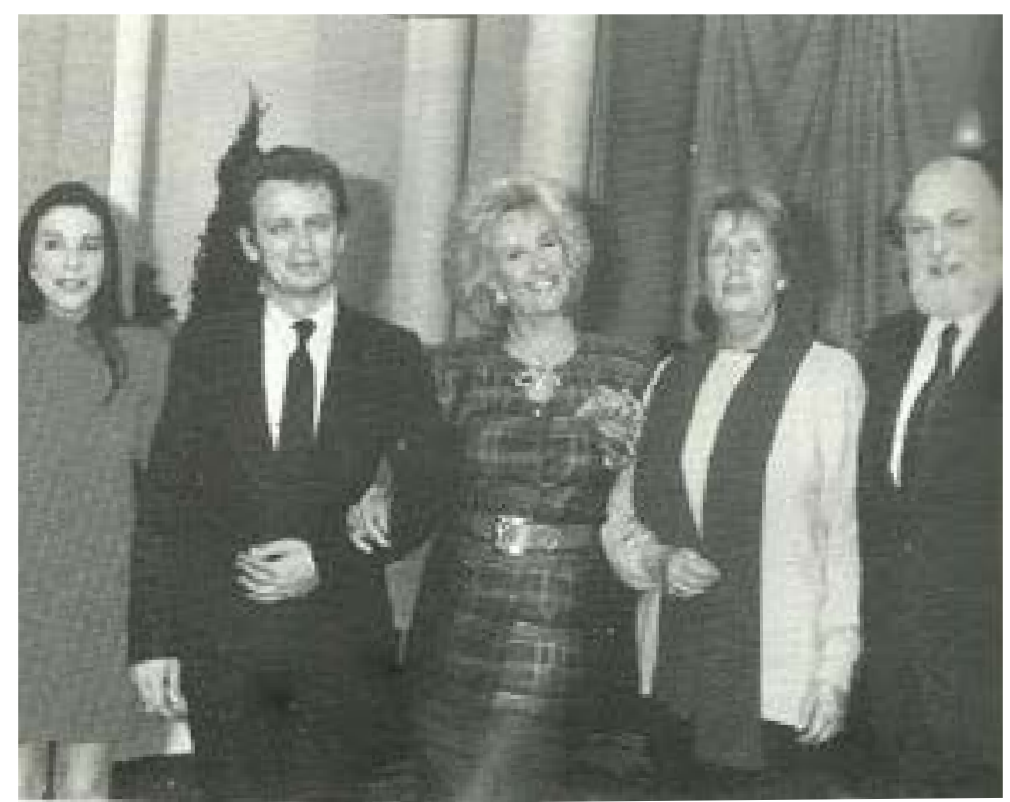

Ilse Fusková junto a Mirtha Legrand. Fuente: Potencia tortillera.

En 1991 un hecho público cobraría gran trascendencia para visibiilizar en la sociedad argentina la existencia lesbiana. “¿Hay muchas lesbianas en la Argentina?, ¿y sospechadas muchas?" La pregunta la realiza la famosa conductora de TV Mirtha Legrand, en un almuerzo que tuvo un importante rating. "Muchas. Pienso que es un gran dolor no poder decirlo abiertamente, porque es como tener una vida dividida, una para afuera y otra en la intimidad", respondió Ilse.

Mis compañeras me decían que no vaya, ique me iban a decir de todo! No les hice caso. Fue tan impresionante la repercusión que tuve que Mirtha quería repetirlo, pero 


\begin{tabular}{c|c} 
Ilse Fusková. & Dra. Karina \\
El cuerpo como archivo & Bidaseca [USAM-AR]
\end{tabular}

no la dejaron. El texto de un sacerdote escrito en un diario decía que yo había dicho algo terrible. ¡No me importó! Habíamos instalado el tema. (apud JÁUREGUI, 2018)

Luego de aquél momento de salida del clóset y visibilidad pública, entre cientos de cartas que llegan a su buzón, conoce a Claudina Marek: "Me vio y se entregó. Estuvimos juntas veintidós años. Fue un ser muy especial y sé que ella no va a salir de mí hasta el último minuto de mi vida", comenta en la entrevista.

Ese día ella estaba engripada y se quedó en su casa mirando televisión. Así, pudo escuchar mi convocatoria a las lesbianas de sentirse orgullosas y dar la cara. Y por esa coincidencia del destino comenzó con ella una historia afectiva y política que duró más de dos décadas. (apud BELLUCCI, 2006).

En 1994 publicaron juntas un libro publicado por Planeta Amor de mujeres. El lesbianismo en la Argentina, hoy. "En él plasmamos nuestras diferentes miradas sobre el amor. Mi mirada hacia las mujeres era más etérea, por lo que el sexo no era para mí lo más importante. Claudina disentía y sobre ese contraste fue que escribimos el libro", nos comenta (apud JÁUREGUI, 2018).

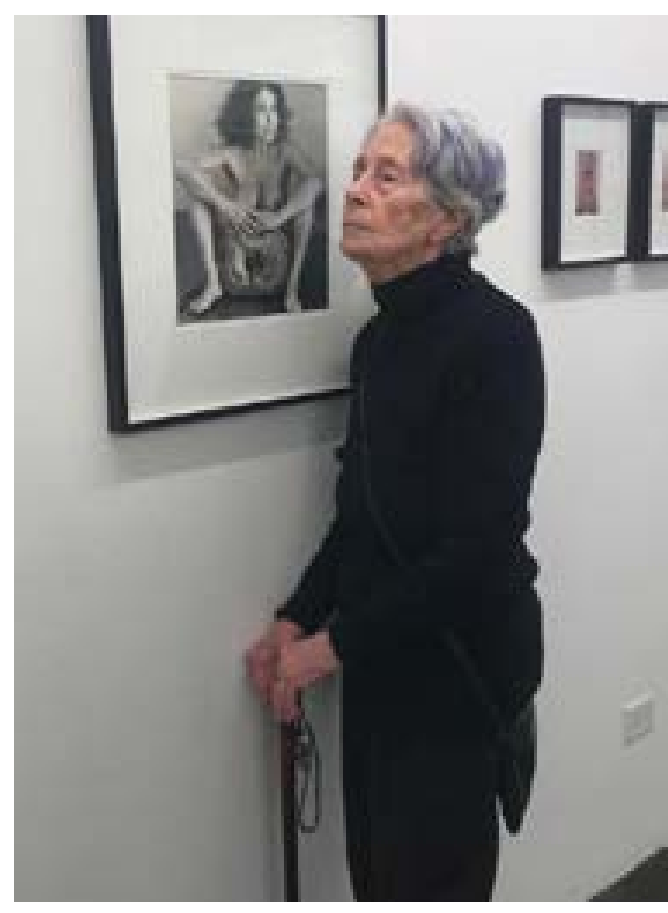

"Es alienante no poder decir lo que una es. Se supone que todos lo saben, todo lo demuestra, pero el silencio cómplice de los demás enloquece.

A quien crea que esto me trajo problemas, le aseguro que no fue así. Por el contrario. El no tener que ocultar ni fingir nada es un canto a la libertad".

Claudina Marek. -LeCtURAS PARA CON-SPIRAR, 1996.

Foto tomada por Karina Bidaseca en Waldengalery,

6 de setiembre de 2019. Buenos Aires. 


\section{Posdata}

Entrevistada junto a la curadora de su muestra reciente en Buenos Aires, en Walden Gallery, María Laura Rosa y Mabel Bellucci, en 2019, Ilse Fusková presentó el libro que lleva su nombre y habló de sus vidas. Llegó acompañada de su hija y un bastón que le brinda sostén y es un símbolo de autoridad.

Antes de comenzar, me permitió tomarle esta fotografía de pefil. Cuidaba cada detalle. Un mechón de su bella cabellera gris plata teñido de color violeta pende hacia su rostro. Y habla, orgullosamente, de un nuevo viaje que la conduce a la aventura de envejecer manteniendo la energía vital de las flores al abrirse.

ANTONACCI, M. A. M. (2018). Áfricas possíveis? Áfricas por si mesmas. In: Anais do III CONGRESO DE ESTUDIOS POSCOLONIALES Y IV JORNADAS DE FEMINISMO POSCOLONIAL, 2016, Buenos Aires. BIDASECA, Karina (org.) Poéticas de los feminismos descoloniales desde el Sur. Buenos Aires: Red de Pensamiento Decolonial (RPD), 2018, 317 p, p. 80-101. Disponível em: http://www.rpdecolonial.com/ publicaciones/Poeticas $\% 20 \mathrm{de} \% 2010$ \% $\% 20$ feminismos\%20descoloniales\%20desde\%20el\%20Sur.pdf. Acesso em: 08 mar. 20.

BELLUCCI, M. (2006) Ilse Fuskova: un testimonio de alto vuelo. Disponível em: http://damiselasenapuros.blogspot.com/2019/01/ilse-fuskova-un-testimonio-de-alto-vuelo.html. Acesso em: 08 mar. 20.

. Una genealogía sobre la violencia hacia las mujeres 1982-1988. In: BELTRAMO, A.; BIDASECA, K.; GHIOLDI, E.; LOIS, I.; LODWICK NUÑEZ, L. Feminismos insurgentes. Buenos Aires: Ed. Caserola Milena, 2019.

BIDASECA, K. (2018). Etnografias feministas posheroicas: la lengua subalterna subversiva de las etnógrafas del Sur. Revista Pléyade, Santiago de Chile, 21, p. 119-140, enero-junio/2018. Disponível em: https:// www.revistapleyade.cl/pleyade/ediciones/numero-21/. Acesso em: 08 mar. 20. . (2013). Feminicidio y políticas de la memoria: exhalaciones sobre la abyección de la violencia contra las mujeres. In: GRIMSON, A.; BIDASECA, K. (org.) Hegemonía cultural y políticas de la diferencia. Buenos Aires: CLACSO, 2013, p. 79-100. Disponível em: http://biblioteca.clacso.edu.ar/clacso/ 
gt/20130721011152/karina_bidaseca.pdf. Acesso em: 08 mar. 20.

. La Revolución será feminista o no será: la piel del arte feminista descolonial. Buenos Aires: Ed. Prometeo, 2018.

CÁMARA FELKÁ. (2018) Página12/Soy, septiembre/2018. Disponível em: https://www.pagina12.com. ar/141760-camara-felka. Acesso em: 08 mar. 20.

DE LAURETIS, T. Queer theory: lesbian and gay sexualities. Differences: A Journal of Feminist Cultural Studies, 3 (2), p. iii-xviii, 1991.

DIAS, G. S. (2019) Fue una pieza clave en la $1^{\circ}$ Marcha del Orgullo y cuenta sus secretos: años de lucha detrás de una noche marcada por "un golpe de suerte". Disponível em: https://www.infobae.com/ sociedad/2019/11/02/fue-una-pieza-clave-en-la-1marcha-del-orgullo-y-cuenta-sus-secretos-anos-de-lucha-detras-de-una-noche-marcada-por-un-golpe-desuerte/. Acesso em: 08 mar. 20.

FUSKOVÁ, I. Ilse Fusková: La libertad de pasear sola. Buenos Aires: Catálogo Walden Gallery, 2019.

. (como KORNREICH, Ilse). "El continuum lesbiano". Cuaderno de existencia lesbiana, I, 1988. Republicado em Revista Brujas, XV, p. 12-14, 1989. Disponível em: http://potenciatortillera.blogspot. com/1989/. Acesso em: 08 mar. 20.

. (como KORNREICH, Ilse); GUIXÉ, Nelda. Luna en la Vereda. Buenos Aires: Walter, 1986.

FUSKOVÁ, I.; MAREK, C. Amor de mujeres: el lesbianismo en la Argentina, hoy. Ed. Por Silvia Schmid. Buenos Aires: Ed. Planeta, 1994.

GLUZMAN, G. G. (2017). Reseña de ROSA, M. L. Legados de libertad: el arte feminista en la efervescencia democrática. Buenos Aires: Biblos, 2014. Revista Mora, 23, p. 229-230, 2017. Disponível em: http:// revistascientificas.filo.uba.ar/index.php/mora/article/ view/5215/4706. Acesso em: 08 mar. 20.
JÁUREGUI, S. (2018) La cámara de Felka. Revista Hamartia. Disponível em: http://www.hamartia.com. ar/2019/03/28/la-camara-de-felka/. Acesso em: 08 mar. 20.

LECTURAS PARA CON-SPIRAR. (1996) Resenha de FUSKOVÁ, I.; MAREK, C. Amor de mujeres: el lesbianismo en la Argentina, hoy. Ed. Por Silvia Schmid. Buenos Aires: Ed. Planeta, 1994. Con-spirando, 16, p. 51. Disponível em: http://www.bibliotecanacionaldigital.gob.cl/visor/BND:167982. Acesso em: 08 mar. 20.

LORDE, A. (1978). BERKSHIRE CONFERENCE OF WOMEN HISTORIANS, IV, 1978, Mount Holyoke College (South Hadley, Massachusetts). Usos de lo erótico: lo erótico como poder. Disponível em: https://sentipensaresfem.wordpress.com/2016/12/03/ ueecpal/. Acesso em: 08 mar. 20.

NERUDA, P. Veinte poemas de amor y una canción desesperada. Santiago: Editorial Nascimento, 1924.

RICH, A. (1996). Compulsory Heterosexuality and Lesbian Existence. In: Blood, Bread and Poetry: Selected Prose 1979-1985. New York/London: Norton, 1986, p. 23-75. Tr. esp. Heterosexualidad obligatoria y existencia lesbiana. Trad. de María-Milagros Rivera Garretas. DUODA: Revista d'Estudis Feministes, 10, p. 15-45, 1996. Disponível em: https://www.raco.cat/ index.php/DUODA/article/view/62008/90505. Acesso em: 08 mar. 20.

Twenty-one love poems. Emeryville: Effie's Press, 1976.

RICHARD, N. Diálogos latinoamericanos en las fronteras del arte: Leonor Arfuch, Ticio Escobar, Néstor García Ganclini, Andrea Giunta. Santiago: Ediciones Universidad Diego Portales, 2014.

ROSA, María L. Legados de libertad: el arte feminista en la efervescencia democrática. Buenos Aires: Biblos, 2014. 
TAYLOR, D. O arquivo e o repertório: performance e memória cultural nas Américas. Belo Horizonte: Editora UFMG, 2013.

WALDENGALLERY. Ilse Fusková. Buenos Aires, 2019.

WALKER, Alice. In Search of our Mothers' Gardens.

San Diego: Harcourt Brace Jovanovich, 1983.

. The color purple. San Diego: Harcourt Bra-

ce Jovanovich, 1982.

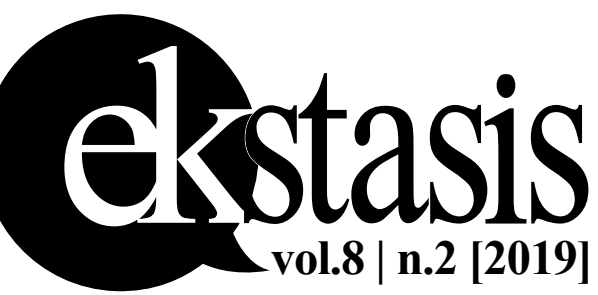

